\title{
The digital transformation and application prospect of military procurement management
}

\author{
Hou Tingting ${ }^{1, *}$, Cheng Rui ${ }^{1}$, and Sun Zhiyu ${ }^{1}$ \\ ${ }^{1}$ The 32524 of PLA, Comprehensive planning room, No. 80 Handan Road Shanghai, China
}

\begin{abstract}
Throughout the military and economic development of various countries and the frontier of public resources, the development from informatization to digitalization and intellectualization has become the inevitable call of The Times. In the era of digital logistics, strengthening the digital management ability of military procurement is an inevitable outcome to meet the needs of modern war. Procurement digital management integrates big data, cloud computing, Internet of Things, process automation and other technologies to help the digital upgrading of traditional procurement links. How to apply digital technology to promote the construction and development of modern military procurement has become a subject worth in-depth discussion.
\end{abstract}

\section{Introduction}

Digital logistics management is an inevitable choice for realizing the sustainable development of logistics management in the information age, and an inevitable requirement for the construction of digital troops and digital battlefields[1]. In recent years, the rapid development of digital technology at home and abroad is subverting the traditional procurement business. As intelligence becomes commonplace, digital management becomes the core competitiveness, procurement will enter the digital era in an all-round way, military procurement must be changed, and transformation is imperative.

\section{Methods and Procedures}

In order to clarify the main problems existing in military procurement in the new period, help find out the methods to improve the problems, and realize the smooth transformation and development of military procurement at the present stage. We organized this survey, mainly in the form of questionnaires, which were sent and received by email. A total of 134 participants were military procurement related personnel (including experts, practitioners and managers). The statistical method was the proportion $=$ the number of votes for a single question/sample number $(\mathrm{n}) * 100 \%, \mathrm{n}=134$.

\subsection{Military procurement focus}

Procurement supervision is the main pain point in all aspects of military procurement. At present, more than $50 \%$ of the respondents believe that the supervision of procurement process is ineffective, and there is a lack of effective supervision over suppliers' violations, that is, the supervision and management of the whole procurement process has become a major pain point. Unifying standards and improving systematic supervision and process will become the main direction of military procurement development. $25.37 \%$ of the respondents believe that the complex procurement process is the main factor affecting the procurement effect. Imperfect procurement system is also one of the main limitations faced by enterprises in procurement. In the face of the above pain points, perfect and compliant procurement design has become the main demand for military procurement. Nearly $20 \%$ of the respondents believe that more efforts should be put into credibility, standardization, cooperation and planning. All of these problems need to be addressed, and the digital transformation of military procurement is urgent. The development trend of digital procurement in China in the "5G" era tells us that the demand of digitized procurement of enterprises has gradually shifted from system platform construction to material master data management, and strengthened the unified management ability and diversified needs of digitized procurement[2]. However, the digital development of military procurement lags far behind. Therefore, the effective use of cloud computing, big data and artificial intelligence technology to build an advanced online platform for military procurement can better improve the military procurement system and promote the transformation of financial resources to strength.

"Hou Tingting: 415667562@qq.com 
Table 1. Military procurement issues focus.

\begin{tabular}{|c|c|}
\hline Issues focus & $\%$ \\
\hline Procurement regulation and enforcement & $51.49 \%$ \\
\hline Suppliers lack of effective management & $50.74 \%$ \\
\hline The procurement system is not perfect & $43.28 \%$ \\
\hline The purchasing control function is weak & $33.58 \%$ \\
\hline Complex procurement process & $25.37 \%$ \\
\hline $\begin{array}{l}\text { Purchasing plan and demand submission } \\
\text { deviation of communication }\end{array}$ & $23.13 \%$ \\
\hline $\begin{array}{c}\text { Review experts are not exclusive rights is too } \\
\text { large }\end{array}$ & $22.38 \%$ \\
\hline $\begin{array}{l}\text { Procurement planning is not standardized and } \\
\text { scientific }\end{array}$ & $20.89 \%$ \\
\hline Procurement process irregularities & $17.91 \%$ \\
\hline Procurement acceptance lacks supervision & $14.17 \%$ \\
\hline $\begin{array}{l}\text { Procurement payment and settlement system is } \\
\text { not perfect }\end{array}$ & $13.43 \%$ \\
\hline Procurement quality is difficult to guarantee & $11.94 \%$ \\
\hline Limited supplier channels & $9.70 \%$ \\
\hline Low procurement efficiency & $8.21 \%$ \\
\hline Limited product selection & $6.72 \%$ \\
\hline Long procurement cycle & $5.22 \%$ \\
\hline Low satisfaction with procurement projects & $4.48 \%$ \\
\hline High procurement cost & $2.99 \%$ \\
\hline other & $2.24 \%$ \\
\hline \multicolumn{2}{|l|}{$\mathrm{N}=134$} \\
\hline
\end{tabular}

\subsection{The digital transformation of military procurement is conducive to the unification of military procurement standard system.}

Standardization is the basis and premise of purchasing digitization. It is an inevitable trend to introduce and prepare for military procurement through digital management of the entire line. By embedding technological advantages such as cloud computing, big data and artificial intelligence into the whole life cycle of military procurement, technological progress can promote institutional optimization. At present, the degree of institutionalization and standardization of military procurement lags far behind the development level at home and abroad. Western militaries have fully launched the era of digital logistics, and the basis of digitalization of logistics is institutionalization, standardization and database construction. Modern warfare requires troops to have a large number of overseas movement and strategic deployment capabilities in a short period of time, which largely relies on advanced global digital visualization of material procurement and supply support capabilities.Starting from the key common procurement business, it is very important to promote the unified construction of the digital platform of the whole army. The unification of procurement standards, service standards and technical standards should be incorporated into the construction of digital standard system for the whole service of military procurement. Build a unified standard, integrated all the purchasing department, and the military procurement process management of cross functional business synergy army purchase digital information platform, realize the procurement business process of digital management, is adapt to the needs of military digital revolution logistics competition, is more advantageous to procurement regulation strictly, put an end to human disturbance, improve the efficiency of procurement, implementation, open and transparent, will push our purchasing modernization construction into the fast lane.

\subsection{The introduction of blockchain technology and thinking is conducive to strengthening the security of military information management.}

Military procurement mainly serves military activities, requiring high confidentiality and strong security, and relying only on human supervision is obviously insufficient. As we all know, the data structure of blockchain technology "block + chain + timestamp" can be used as proof of existence and form proof that cannot be tampered with, which provides a strong guarantee for the security of military procurement. When there is a leak, can be at any time for proof and accountability. Blockchain technology builds a complete protocol mechanism that allows each node to verify the correctness of other nodes' information while recording, without the need for third-party authority to endorse the information. This protocol mechanism creates trust and consensus among participants, and also provides a security barrier to the confidentiality of military procurement[2]. To apply this kind of thinking mode in the procurement process all the elements of data management, to form a very close monitoring network, become the network management of the natural barriers, let the human, human intervention, tampering with information, achieve confidentiality function at the same time, realize regional purchasing management scientific, information-based and precision.

\subsection{Digital online management of the whole process is conducive to one-stop quality evaluation management of military procurement activities.}

Digital purchasing management through the application of artificial intelligence, Internet of things, cloud technology, process automation and collaborative network technology, build predictive strategy to find the source, automated procurement execution and prospective supplier management[3], to implement the whole process of purchasing online controls, to purchase evaluation data acquisition, real-time analysis and quality assessment to provide scientific basis and effective regulation. (1) Create online management of the whole life cycle of suppliers through digitalization, and realize online control of supplier performance evaluation. Full life cycle management including supplier development, 
certification introduction, performance evaluation and risk management, and supplier abolition. (2) Online evaluation of the procurement process. Build digital procurement online sourcing, make the traditional procurement process online, realize the scientific and transparent control of the procurement process, seek the optimal solution of procurement results, and improve the scientific and refined degree of procurement management evaluation. (3) Real-time online coordination of procurement business. Through the optimization of internal and external coordination mechanism, the orderly flow of data is realized, and the benign collaboration between the demand end, the purchasing function organization and the supplier is promoted. The quality evaluation system is to achieve the purpose of saving procurement cost and improving procurement efficiency and benefit by speeding up the sorting of all levels and all kinds of relationships. At present, there is still a big gap between the military procurement and digital development goals, so it is necessary to further strengthen the construction of military procurement digital information platform, and create a favorable technical environment for the development of military procurement.

\subsection{With the help of intelligent supervision, it is conducive to promoting the perfection of military procurement supervision system to make up for the lack of human supervision.}

There are some problems in the supervision of military procurement in China, such as lack of independent supervision subject, imperfect supervision system, imperfect supervision rules, and unsystematic supervision content. Intelligent supervision is introduced, and intelligent bid evaluation "intelligent prompt + intelligent clear bid" is used to realize intelligent supervision based on data and machines in bid evaluation conclusion. The solution to the injustice of experts and the lack of supervision of human resources. Interests at the same time, the construction of real-time supervision, rewards and punishment system and guarantee system, data analysis and decision support system, as a rule in put in procurement process, all procurement activities in evidence, the results made public, sunlight, transparent, advance warning of abnormal purchasing behavior, matter monitoring, afterwards the traceability of the early warning system for real-time intelligent supervision of comprehensive[4]. In the future, the intelligent supervision system of using digital technology for business supervision, audio and video online supervision, big data supervision and block chain supervision will realize the "omni-directional and non-dead corner" of platform transaction supervision.

\subsection{The construction of a cloud platform with multiple elements converges into one, which is conducive to building an efficient and clean procurement force that ADAPTS to the needs of modern war and military development.}

It is our aim to build an efficient and honest procurement force to meet the needs of modern war. In the context of "Internet +", military procurement also actively embraces big data, and with the help of powerful e-commerce resources, builds an advanced multi-factor convergence cloud platform for military procurement. Under the premise of ensuring the legality and compliance of procurement, required materials can be purchased in a more timely and accurate way to save costs. The centralized procurement project of e-commerce platform carried out by a military at the beginning of this year is the implementation of intelligent and digital upgrading of military material procurement, which will accelerate the realization of cost reduction and efficiency increase in military material procurement.

\subsection{Drawing on the government procurement platform, we will create a new pattern of integrated military-civilian development in military procurement in a new era.}

The establishment of a military-civilian data exchange and information sharing mechanism can not only guide the military to improve the bulk purchase of medicinal materials, instruments, equipment, clothing and other materials, but also give priority to the sharing of energy-saving, green and environment-friendly products that meet the needs of national defense and the military, expand the achievements of resource sharing, and achieve "win-win" economic and social benefits. In addition, we will continue to deepen resource integration and sharing, and actively expand the channels for social procurement forces to "join the army". On the basis of existing army procurement regulations, based on military procurement business platform, gradually introduce local bidding agent, cost consultation, legal services, appraisal quality inspection and other professional institutions, to undertake the project army not classified purchasing task, has successfully taken the first step, in a timely manner to solve the army itself purchasing power than the reality of the contradiction. At the same time, by connecting with the national credit system, the same products purchased by the military and local governments from a single source will be promoted, and cross-network connection will be promoted with national government procurement, engineering construction, material import, drug supply guarantee and other platforms, and the price evaluation results will be shared and mutually recognized. This will have more realistic guiding significance in the future.

\section{Conclusion}

In the future, the digital ecology of military and civilian resources will be integrated online through big data, 
cloud technology and blockchain and other advanced digital technologies. Realize the military and local "two databases" resource sharing. Connect with the national credit system and the joint punishment mechanism of purchasing credit, and communicate with each other to recognize the credit system of suppliers and review experts. We will implement the concept of green development and guide the armed forces to give priority to the purchase of green, energy-saving and environment-friendly products that meet the needs of national defense and the armed forces. We will promote the cross-network connectivity of the Internet of Things platform, accelerate the establishment of data exchange and information sharing mechanisms, take military procurement and government procurement services into overall consideration and advance in a coordinated manner, promote the alliance of purchasing forces to jointly reduce costs and increase efficiency, and accelerate the transformation and development of the procurement industry.

We will deepen resource integration and sharing. Fully docking with national and provincial (municipal) review expert database and supplier database, expanding professional coverage, and realizing the sharing of military and local "two databases" of resources. To connect with the national credit system, to establish a trans-regional, trans-departmental and trans-field joint punishment mechanism for purchasing credit together with relevant national departments, and to communicate and recognize suppliers and review the credit status of experts. Implement the concept of green development, introduce a national list of energy-saving and environment-friendly products, and guide the armed forces to give priority to purchasing energy-saving and environment-friendly products that meet the needs of national defense and the armed forces. To meet the requirements of national medicinal materials procurement policies, the procurement results system of military medicinal materials procurement applicable to local governments was improved. We will encourage the military and local governments to purchase similar products from a single source, and share and recognize the price evaluation results. We will take the lead in demonstration projects. We will step up the construction of military-civilian integration demonstration projects for military procurement platforms, promote cross-network connectivity with national government procurement, project construction, material import, and drug supply guarantee platforms, and establish data exchange and information sharing mechanisms. We will promote the experience of the pilot project of centralized procurement of military official air tickets, make the procurement of military services and government purchase services under overall consideration and coordination, and promote the sharing of purchasing forces.

\section{Acknowledgements}

Thanks to write papers help experts and colleagues, special thanks to the procurement authority Li Songtao, director of the great support.

\section{Reference}

1. Peng xiuyuan, Modern Economic Information, 8, (2015) .

2. Ai rui, Research Report of iResearch Consulting Series, $12,2020$.

3. Wu yu, China Tender, 48, (2018).

4. Zhang yi, Wang yuhua, Wang qifei, Journal of Shanghai Administration Institute, 2, 2020. 